\title{
Formação de professores e programas de ensino de Matemática nos institutos normais de educação: uma análise da Escola Primária da Bahia (1836-1960)
}

\author{
Formation of teachers and programs for teaching materials in the normal \\ education institutes: an analysis of the Primary School of Bahia (1836-196o)
}

Formación de profesores y programas de materiales de enseñanza en los institutos de educación normales: un análisis de la Escuela Primaria de Bahía (1836-1960)

\author{
ROSEMEIRE DOS SANTOS AMARAL ${ }^{1}{ }^{1}$ \\ IRANI PAROLIN SANTANA ${ }^{2}$ \\ Claudinei de Camargo Sant'Ana@ 3 \\ ${ }^{1}$ Universidade Federal de Sergipe, Aracaju, SE, Brasil. \\ ${ }^{2}$ Universidade Estadual do Sudoeste da Bahia e Sociedade Brasileira de Educação Matemática na Bahia, \\ Vitória da Conquista, BA, Brasil. \\ ${ }^{3}$ Universidade Estadual do Sudoeste da Bahia - UESB, Sociedade Brasileira de Educação Matemática na Bahia, SBEM/Ba.
}

\begin{abstract}
RESUMO
Esta pesquisa tem por objetivo uma análise histórica dos cursos de formação de professores e dos programas de ensino de Matemática para a escola primária na Bahia entre 1836 (ano da instituição da primeira escola normal do Estado) e 1960 (década demarcada pelo Movimento da Matemática Moderna), levando-se em conta as reformas educacionais estaduais de 1890, 1913, 1918 e 1925 e as determinações para estrutura e funcionamento do Ensino Primário e dos Institutos Normais de Educação. As fontes históricas documentais, em especial as alocadas junto ao Repositório da Universidade Federal de Santa Catarina (UFSC), são parte do constructo investigativo: Quais as permanências e rupturas referentes aos cursos de formação de professores e aos programas de ensino de Matemática pautadas na legislação educacional e nas práticas pedagógicas das escolas normais e da escola primária da Bahia entre 1836 e 1960 ? Os resultados da pesquisa elaboram uma trajetória da escola normal, bem como do ensino de Matemática no Brasil, em particular, na Bahia, séculos XIX e XX.
\end{abstract}

Palavras-chave: Bahia (1836-1960). Escola Primária. Formação de Professores. Programas de Ensino de Matemática. Institutos Normais de Educação.

\begin{abstract}
The objective of this research is a historical analysis of the Teacher Training Courses and the Mathematics Teaching Programs for the Primary School in Bahia between 1836 (year of the institution of the first State Normal School) and 1960 (decade demarcated by the Modern Mathematics Movement), taking into account the state educational reforms of 1890, 1913, 1918 and 1925 and the determinations for the structure and functioning of Primary Education and the Normal Institutes of Education. The historical documentary sources, especially those allocated to the Repository of the Federal University of Santa Catarina (UFSC), are part of the investigative construct: What are the stays and ruptures related to the Teacher Training Courses and the Mathematics Teaching Programs based on the educational legislation and pedagogical practices of the Normal Schools and the Primary School of Bahia between 1836 and 1960 ? The results of the research elaborate the trajectory of the Normal School, as well as the teaching of Mathematics in Brazil, in particular, in Bahia, in the 19th and 20th centuries.
\end{abstract}

Keywords: Bahia (1836-1960). Primary School. Teacher Training. Mathematics Teaching Programs. Normal Institutes of Education.

\section{RESUMEN}

El objetivo de esta investigación es un análisis histórico de los Cursos de Formación de Profesores y de los Programas de Enseñanza de Matemáticas para la Escuela Primaria de Bahía entre 1836 (año de la institución de la primera

\footnotetext{
1 A pesquisa integra o Projeto “O ensino de Matemática no Curso Primário da Bahia: a caracterização de um percurso" patrocinado pelo CNPq, sob processo no 407925/2016-3.
} 
Escuela Normal Estatal) y 1960 (década demarcada por el Movimiento Matemático Moderno), teniendo en cuenta las reformas educativas estatales de 1890,1913, 1918 y 1925 y las determinaciones para la estructura y funcionamiento de la Educación Primaria y de los Institutos Normales de Educación. Las fuentes documentales históricas, especialmente las asignadas al Depósito de la Universidad Federal de Santa Catarina (UFSC), forman parte de la construcción investigativa: ¿Cuáles son las permanencias y rupturas relacionadas con los Cursos de Formación de Maestros y los Programas de Enseñanza de Matemáticas basados en la legislación educativa y las prácticas pedagógicas de las Escuelas Normales y de la Escuela Primaria de Bahia entre 1836 y 1960? Los resultados de la investigación elaborar una de la trayectoria de la Escuela Normal, así como de la enseñanza de las Matemáticas en Brasil, en particular, en Bahía, en los siglos XIX y XX.

Palabras clave: Bahía (1836-1960). Escuela Primaria. Formación de profesores. Programas de Enseñanza de Matemáticas. Institutos Normales de Educación.

\section{A Instrução Pública na Bahia: uma PERSPECTIVA HISTÓRICA DAS ESCOLAS PRIMÁriAs E ESCOLAS NORMAIS}

A História da Instrução Pública na Bahia remetenos aos anos iniciais do século XIX, quando "a primeira legislação educacional na província da Bahia data de 1835, ano em que o Ato Adicional à Constituição de 1824 atribui às Assembleias Legislativas Provinciais a função de legislar sobre o ensino primário" (D’ESQUIVEL, 2015, p. 17).

Dentre os instrumentos alcançados durante a investigação a respeito da formação de professores e os programas de ensino de Matemática nos institutos normais de educação e das escolas primárias da Bahia, relevantes fontes históricas documentais, estão os Relatórios de Administração Pública do Estado, que apresentaram em anexo as Fallas $^{2}$ e Relatórios dos Presidentes provinciais no Império (1830-1889), os quais "faziam parte das atribuições do governo nas sessões da Assembléa Provincial, quando dava conta de suas ações, sucessos, projetos e problemas. Em muitas das Fallas e Relatórios dos presidentes de província não constam. Noutras, são minuciosos e precisos" (SOUSA, 2011, p.3, grifo do autor). Esse material, por seu caráter governamental, escrituração oficial, junto às prescrições da Legislação Educacional da Bahia (1830-1960), é primordial para a investigação sobre a trajetória do ensino de Matemática no Brasil, em particular na Bahia, nos séculos XIX e XX.

Rocha (2008, p. 2) alertou que "na Bahia, os Presidentes de Província exerciam o cargo por pouco tempo e essa descontinuidade fazia com que sua ingerência na vida social, econômica e política da província fosse passageira. E a instrução pública vivia ao sabor dessa oscilação". Em 1830, o Presidente da Província, Luiz Paulo de Araujo Basto (1830, p. 1), em uma "falla" aos

\footnotetext{
2 Em respeito às fontes históricas documentais, a transcrição manteve a escrita em sua originalidade.
}

Conselheiros Gerais, proclamou: "eu tenho hoje a honra de dar, Srs., uma noção geral do estado dos negócios públicos, e seguida dos esforços, e patriotismo de tão illustres e Dignos Cidadãos, espero que a Provincia verá em resultado as mais sabias providencias para o seu melhoramento".

Antecipando-se ao Ato Adicional, Basto (1830, p. 1), naquela oportunidade, considerou que a instrução dentro do âmbito estadual estava em ascensão, à medida que "pelo conhecimento de si próprio prepara o Cidadão para se interessar pelo Estado, e amar as Instituições liberaes, que tanto convém, arreigar em nossa Patria". A escola teria como função incutir noções de civilidade (obediência ao rigor e padrões culturais), nacionalidade (o pertencimento a uma coletividade) e progresso (por meio dos estudos e trabalho). Havia um otimismo por uma criação de escolas elementares, enfatizando as instituições de ensino na capital:

[...] só dentro da Capital há quatro Collegios de educação, a saber o dos Orfãos, e tres particulares, desesete Aulas publicas de estudos preparatórios, desenove ditas particulares, sendo o maior numero destas nos Collegios, vinte e tres Aulas publicas de Primeira Letras, vinte e duas ditas particulares; entre as Aulas publicas há já duas, que ensinão perfeitamente pelo Systema de ensino mutuo, e tres entre as particulares; há mais o Collegio MedicoCirurgico. O numero em todas as Aulas he de dois mil quinhentos e trinta e cinco, em que ha augmento comparativamente com os alumnos, que as frequentavão no ano passado, especialmente quanto ao sexo feminino (BASTO, 1830, s/p, grifo nosso).

Um fator destacado por Basto (1830) foi a adesão ao ensino mútuo ${ }^{3}$ nas aulas públicas, o aumento do quantitativo de alunos (2.535) e, dentre estes, os do sexo

\footnotetext{
${ }^{3}$ O princípio do ensino mútuo era que todos os alunos tivessem submetidos às mesmas regras e qualquer um deles pudesse progredir pelo mérito individual (HILSDORF, 2001, p. 73).
} 
feminino. D'Esquivel (2015, p. 18) sustentou que “o Método de Ensino Mútuo foi amplamente adotado pelas escolas normais no Brasil durante a segunda metade do século XIX, contribuindo para a instauração de uma cultura de valorização do espaço escolar".

Em 1839, o presidente provincial Thomaz Xavier Garcia de Almeida, ainda considerando um devido progresso, iniciou em sua "falla" uma crítica em relação à postura do professor de instrução primária, particularmente, os que se encontravam no interior. Esse comportamento se deveu, antes de tudo, pela "falta de um meio eficaz, que obrigue os Professores a cumprir com os deveres do Magistério, ocorre-me de authorizardes o Governo para suspende-los correccionalmente, e mesmo demiti-los [...]" (ALMEIDA, 1839, p. 11-12).

Quanto à formação dos professores destinados para as escolas normais e complementar, uma expressa atenção/cuidado, visto o declarado: "já estão em França, estudando as matérias em que forão mandados instruir-se; do nosso Ministro residente em Pariz recebi participação, de que eles procuravão desempenhar as suas obrigações" (ALMEIDA, 1839, p. 13). Essa informação foi endossada por D'Esquivel (2015, p. 19): “na Bahia, a primeira escola normal é criada em 1836, mas só veio a funcionar de fato em 1842, com o retorno da França dos professores João Alves Portella e Manoel Correia Garcia, que haviam sidos enviados em missão de estudos".

São os primeiros indícios de uma preocupação com a formação de professores baianos, o envio para outros países, a exemplo da França, a fim de especializarem-se e retornarem ao Estado para atuarem junto aos normalistas. Com a ausência de professores especializados para atuarem nos cursos normais, estando alguns fora do país, muitas cadeiras se encontravam "vagas" ou à espera de que fossem ocupadas, em diferentes cursos e esse processo de formação no exterior que não se constituía um ato tão simples, passou a ser uma regra e demandava tempo:

[...] deixão a consoladora ideia de que a instrucção dos jovens Bahianos não he desprezada... No mesmo estado de concurso se acha a cadeira Complementar da Escola Normal do Ensino Mutuo, mandada crear pela Lei de 14 de Abril de 1836. Os indivíduos que, em consequência dos exames para poderem obter os lugares de professor e monitor geral desta escola, farão estudar à França, regressarão já com suas habilitações, e se lhes expedirão os competentes diplomas (AZEVEDO, 1841, p. 12, grifo nosso).

Como citado, o ensino mútuo chegou à Escola Normal da Bahia, pelo menos, em linhas gerais deliberativas, constante na Lei de 14 de abril de 1836 e da qual dependiam três escolas primárias, "que se deverão prover depois que a escola Normal habilitar os concorrentes" (AZEVEDO, 1842, p.15). Todavia, "a utilização pelas escolas primárias das prescrições do Método de Ensino Mútuo é anterior a sua utilização no curso de formação de professores da primeira escola normal em 1836. Esta, no entanto, concorrerá para a oficialização do uso do método" (D'ESQUIVEL, 2015, p. 33).

Um problema recorrente, em 1842, é o papel atribuído ao professor primário e as suas respectivas ações. Paulo José de Mello Azevedo (1842, p.15-16), o então presidente, analisou em sua "falla" que, mesmo os professores possuindo aptidão necessária aos serviços do ensino, o descaso para com a instrução pública se tornava tão evidente que o cargo era abandonado em função de duas situações principais: a) doença - sendo oficialmente comprovada ou forjada: "observo com bastante desgosto, que sendo robustos, e vigorosos quando pretendem as cadeiras, mais de metade interrompem o ensino, dizendose impossibilitados por doentes, o que comprovam por certidões de facultativos de medicina, e cirurgia" (AZEVEDO, 1842, p. 15); e b) uma oportunidade em outro setor, como o convite ou candidatura a cargos públicos: "outros sendo eleitos para certos cargos públicos, que os inibem de reger por si suas cadeiras, as entregam à substitutos mal pagos à sua custa, que não tem a necessária aptidão" (AZEVEDO, 1842, p. 16), dando espaço aos contratos.

D'Esquivel (2015, p. 20) atestou que "as contratações de professores nem sempre puderam fazer cumprir as prescrições oficiais de que, para apenas professores formados pela escola normal, era permitido assumir Cadeiras nas escolas de ensino primário". O que suporia um aspecto positivo para a formação do professor primário, a existência de concurso, ocasionou um efeito adverso. Primeiro, devido à demora em que se realizava o processo seletivo, das inscrições até as nomeações dos referidos; segundo, a possibilidade de um candidato aprovado abrir mão de seu posto, mas deixar provisoriamente ou por tempo indeterminado, outro profissional, habilitado ou não. Algumas consequências se tornaram inevitáveis, como: "o descredito das escolas, e o desproveito dos alumnos, cujos pais antes preferem a professores particulares com sacrifício de despesas" (AZEVEDO, 1842, p. 16).

A Escola Normal, para o ano de 1842, passou a dirigir as escolas primárias, assegurando assim uma correlação entre as duas instâncias de ensino:

A Escola Normal, que já tem promptos os arranjos necessários, vai começar seus trabalhos no principio de março próximo futuro, conforme tem assegurado o respectivo director, o qual devendo também dirigir todas as escolas primarias, que estava, à cargo do Lyceo, e pelos estatutos deste estabelecimento deixarão 
de estar, acaba de organisar dous regulamentos, um para aquella, e outro para estas, que deverão ser inspecionadas por dous inspectores propostos por elle, e approvados pelo governo (AZEVEDO, 1842, p. 16).

Com a existência de um regulamento específico para a Escola Normal e outro para as escolas primárias, ambas deveriam pautar-se no ensino mútuo, contanto que possuíssem seus respectivos inspetores. Porém, "a iniciativa de estender para as escolas primárias o ensino através do Método Mútuo, que já vinha sendo aplicado na escola normal, parece não ter tido grande impacto na organização do ensino primário para a maioria das escolas da província da Bahia" (D’ESQUIVEL, 2015, p. 23), ou seja, não havia uma uniformidade nas práticas culturais escolares, dentre elas, em relação aos currículos e programas de ensino, ponto chave das futuras reformas educacionais de cunho nacional.

Tendo havido essa iniciativa, Vasconcelos (1843, p. 13-14, grifo nosso) destacou que

as escolas primarias cujo numero consta do orçamento da despeza, acham-se providas com excepção de seis, que se não podem provêr, sem que a Escola Normal (creação que me parece mais dispendiosa que proveitosa) habilite os concorrentes.

Nesse contexto, Vasconcelos denotou dois apontamentos: 1) O dispêndio com a criação de escolas normais em lugares periféricos, pois "as maiores continuam a ser pouco frequentadas, mórmente as que ainda existem nas comarcas" (VASCONCELOS, 1843, p. 14); 2) Embora o número de escolas primárias, provavelmente, ascendeu, mas deste, em um prazo de um ano, dobrou-se o quantitativo sem a assistência da Escola Normal, de 3 em 1842 para 6, em 1843. Em um balanço, Vasconcelos (1844, p. 15) retomou o seu diagnóstico, concluindo que alguns problemas persistiam na instrução pública baiana:

\begin{abstract}
A instrucção publica poderia ter produzido melhores resultados, se fosse possivel introduzir no animo dos Professores, a quem não falta aptidão, o propósito firme de desempenharem suas obrigações com assiduidade, mas observo com desprazer, que a negligencia d'uns, e as enfermidades verdadeiras, ou falsas de outros, roubam à mocidade, ou lhe retardam o goso da necessária instrucção.
\end{abstract}

Por outro lado, Vasconcelos (1844, p. 15), demarcou um maior acesso ou ingresso da população menos provida de recursos financeiros às escolas primárias, divulgando um caráter de educação popular: "Porém he necessario confessar, que assim mesmo a instrucção primaria achase hoje mais generalizada pela massa do povo, do que nos annos anteriores ao de 1835", ficando de fora os indigentes e os que moravam distantes. Um ano depois, a constatação feita pelo presidente provincial Francisco José de Sousa Soares D'Andreia (1845, p. 32-33) não foi das melhores:

a Instrucção Publica está mal n'esta provincia, está mal por toda parte, e não he de certo por falta de Cursos Juridicos, de Escola de Medicina, Academias de todas as qualidades, Liceos, Escola Normaes, e Professores de quantas cousas lembram, que tudo se aceita, tudo se approva, tudo aumenta a despeza, e tudo fica no mesmo estado.

A situação ficou tão complicada que havia "uma Escola Normal com três Professores, sendo um deles o Director" (D'ANDREIA, 1845, p.33), evidenciando a precariedade com que funcionavam as Escolas de formação de professores em meados do século XIX. D'Esquivel $(2015$, p. 20$)$ enalteceu que "entre o surgimento nos anos 1830 e 1840 e o funcionamento durante a segunda metade do século XIX, as escolas normais fundadas no Brasil caminham entre extinções, reaberturas, mudanças curriculares, reformas, mudanças de prédio etc."

Comparando-se a Bahia com o restante do país e até em nível internacional, em termos históricos e cronológicos, o Estado acompanhou o movimento da implantação das escolas normais, visto que a Escola Normal de Niterói, criada sob a Lei n⿳⺈ 10 , de 4 de abril de 1835, foi a primeira deste porte no Brasil, "uma importante instituição de formação de professores no Império. Embora não se situasse na Corte, exerceu grande influência nas decisões sobre a esfera educacional" (VILLELA, 2000, p. 105). Notoriamente conhecida por ser a "pioneira na América Latina e, de caráter público, a primeira de todo o continente, já que nos Estados Unidos as que então existiam eram escolas particulares" (ROMANELLI, 1978, p.163), não teve um percurso duradouro, sendo extinta em 1849.

Na Bahia, Lemos (2011) ressaltou que a Lei no 37 do ano de 1836, sancionou a criação da Escola Normal, pelo Presidente da Província Dr. Francisco de Souza Paraíso. No entanto, com as intransponíveis variações, em 1850, a Resolução no 403 de 2 de agosto, dirigida especificamente ao Curso Normal, determinou a separação entre os sexos e a Lei no 844, do ano de 1862, decretou um regime de internato, tanto masculino quanto feminino, que perdurou até 1864. De acordo Assis (2008, p. 2), até o ano de 1947, "a Bahia só podia contar com um colégio secundário oficial, o Centenário Colégio Estadual da Bahia, o atual "Instituto Central de Educação Isaías Alves", e duas escolas normais Rurais, uma em Caetité, zona da Serra Geral, e outra em Feira de Santana".

A Escola Normal de Caetité, a segunda Escola Normal Instalada no Estado da Bahia, 
foi criada pela Lei $\mathrm{n}$ o 117 de 24/08/1895, sendo inaugurada somente em maio de 1898, no governo de Dr. Joaquim Manoel Rodrigues Lima, O curso tinha a duração de 04 anos e era destinado às moças. Diplomou três turmas, num total de 32 professoras, até o ano de 1903, quando seu funcionamento foi interrompido (REIS, 2008, p. 65).

A Escola Normal Feira de Santana, criada em 1925 e inaugurada em $1^{\circ}$ de julho de 1927 , formou a primeira turma de normalistas. No ano de 1949, passou a ser Ginásio Estadual de Feira de Santana, "momento em que deixa de formar apenas professores e passa também a se dedicar à formação de técnicos de nível médio no Curso de Administração" (CRUZ, 2010, p. 198).

Magalhães (1848, p.9) apresentou uma posição de dupla direção, quando afirmou: "posto que a Instrucção Publica tenha obtido alguns melhoramentos entre nós, com tudo ainda está mui distante da desejada perfeição". Destacando a importância da instrução para a formação do cidadão, enfatizou:

Se, como ninguém ignora, uma das causas mais influentes na perpetração dos crimes he a falta da instrucção necessária para desenvolver o estado intelectual, e moral do homem, que tende a aperfeiçoar-se, e colocar-se ao nível do estado progressivo e real da Sociedade, bem como se vê, que este he um dos ramos da Administração Publica, que deve primeiro receber todos os nossos disvellos, e cuidados (MAGALHÃES, 1848, p.9, grifo nosso).

Com o intuito de alargar o atendimento da instrução pública, compreendeu que esta "deve ser derramada o mais possível por todas as suas diversas classes. Infelizmente as Aulas elementares da Provincia ainda não satisfazem suas necessidades, e essas mesmas se achão em máo estado" (MAGALHÃES, 1848, p. 10). Mas, para que isso ocorresse, inúmeros fatores deveriam ser superados, como a falta de recursos materiais e um sistema de ensino unificado: "A ignorância, e neglicencia dos Professores, a falta de Compendios, e utensílios, de unidade, e uniformidade no ensino, tudo concorre para esse deplorável atraso, em que ainda se acha a instrucção elementar" (MAGALHÃES, 1848).

Magalhães (1848, p. 11, grifo nosso) inaugurou uma possível política de valorização da profissão docente e, ao mesmo tempo, a recuperação do status da escola primária pública mediante as famílias, quando refletiu:

Cabe aqui ponderar, que não obstante a imperfeição das nossas Aulas elementares, muitos Professores são assíduos no ensino, e cumprem com seus deveres: em geral são eles mal retribuidos, sendo certo que as funções mal pagas, são mal preenchidas.
Se quereis bons Professores he necessario que sejao melhor estipendiados, e, adstrictos a passarem por um crivo de provas mais severas, que attestem de modo incontroverso sua aptidão, e idoneidade.

Considero os Professores Publicos compreendidos n'esta these, e julgaria conveniente que se lhes concedesse uma gratificação por um certo numero de alumnos, que no fim do curso litterario fossem approvados, mediante exame serio, que atestasse o seu aproveitamento. He um estimulo que se thes proporcionaria, para que augmentassem o numero dos discípulos, inspirando confiança ás famílias.

Estímulo. Esse seria o segredo para a ascensão da escola, tanto em nível primário quanto normal, para alunos, professores e sociedade em geral, em especial, para as famílias, segundo Magalhães, em 1848. As "fallas" entre 1849 e 1883 referem-se às estatísticas, com ênfase na obrigatoriedade escolar (1876) e nas reformas na Instrução, descritas a seguir.

\section{AS REFORMAS dA INSTRUÇÃo PÚBLICA NO ESTADO DA BAHIA}

A primeira Constituição do Estado da Bahia data do ano de 1890, mas só foi homologada em 1891. Não obstante, a elaboração da Resolução Complementar relativa à educação exigida pelo texto constitucional só foi concebida no ano de 1895 (ARAÚJO; SOUZA; PINTO, 2012), "sendo o primeiro Regulamento do Ensino Primário do estado, estabelecido pelo Ato de 4 de outubro do mesmo ano, responsabilizando os órgãos estatais pela criação e manutenção de escolas para os anos iniciais" (AMARAL, 2015, p.21), ao que denominamos reforma pregressa da legislação da instrução pública baiana. De acordo os seus preceitos, os processos de ensino deveriam ser os de intuição e os programas, horários, livros e o demais materiais didáticos aprovados pelo Conselho Superior de Ensino (BAHIA, 1895).

D'Esquivel (2015, p.45) assinalou que "impulsionados pelas mudanças pedagógicas que se processam no último quartel do século XIX é que, nas legislações educacionais da Bahia, os currículos para a escola normal de formação de professores e para a escola de ensino primário se complexificam". Por exemplo, para ser professor do Ensino Primário na Bahia, em 1895, a legislação prescreveu:

Art. 22. Ninguém poderá exercer o magistério publico primario elementar sem que exiba diploma de alumno-mestre, conferido pelas escolas normaes do Estado ou dos municípios, e prove:

a) Idoneidade moral com attestado de paes de família bem reputados, e das auctoridades de seu domicilio. 
b) Que não sofra moléstia, ou defeito physico incompatível com as funções do magistério (BAHIA, 1895, p. 253, grifo nosso).

Como o cargo de professora era cotado por senhoras, a Lei estabelecia no Parágrafo único: “As senhoras provarão, sendo casadas, ou viúvas, o seu estado mediante certidão; sendo casadas mas separadas judicialmente, que - o motivo determinante da separação não lhes é deshonroso, mediante certidão verbum ad verbum das respectivas sentenças" (BAHIA, 1895, p.48, grifo do autor). Ainda em relação à assunção ao cargo, o Art. 23, estipulou:

Não poderá exercer o magistério publico primario estadual ou municipal o indivíduo que:

a) Houver perdido emprego federal, estadual ou municipal em virtude de sentença judicial;

b) 'Houver sofrido condenação por crime contra a propriedade, a moralidade e os bons costumes;

c) Houver perdido a cadeira de ensino publico por sentença em processo disciplinar (BAHIA, 1895, p.48).

Apesar de todo esse quadro de exigências, é fato que "antes mesmo da implantação da escola normal, já existiam Cadeiras para o ensino primário. Os professores que ocupavam essas Cadeiras, quase todos leigos, exerciam o ofício de professor à revelia das orientações do Estado" (D'ESQUIVEL, 2015, p. 20).

Em 1895, a escola elementar é a que se refere à escola

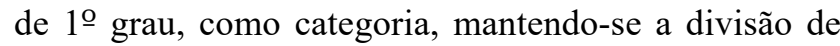
acordo com o grau de classificação ou níveis de ensino de cada categoria: "Os alunos destas escolas serão classificados em três cursos: a) Elementar; b) Médio; c) Superior" (BAHIA, 1895, p.61) e deveriam seguir as orientações pedagógicas das escolas anexas ao Instituto Normal (BAHIA, 1895).

A Lei $n^{0}$ 1006, de 6 de setembro de 1913, foi considerada a segunda mudança mais abrupta na legislação educacional da Bahia, que decreta uma "Reforma no Ensino Primário do Estado" e designou no "§ $2^{\circ} \mathrm{O}$ ensino elementar se dará em 4 annos cujo programma será integral para as escolas de primeira classe, e proporcional as de segunda e terceira e se desdobrará deste plano geral" (BAHIA, 1913, p. 136).

Ao que tudo indica, a instrução pública baiana passou por um período de estagnação ao que se refere às reformas entre 1913 e 1920, “[...] não houve mudanças significativas. Somente a partir da década de 20, em virtude do Movimento Escolanovista, liderado na Bahia pelo ilustre Anísio Teixeira, a educação retoma seus processos de reformas" (LEMOS, 2011, p. 7).

Em 1925, as escolas normais foram definidas constitucionalmente como institutos destinados a formar professores para o ensino primário: "Art. 119. O Governo manterá, por enquanto, quatro escolas normaes para alumnos de ambos os sexos, sendo uma na Capital e as outras em cidades do interior" (BAHIA, 1925, p. 198). A legislação de 1925 pautou no Artigo no 139 uma lista de recursos aos normalistas para o ensino prático nas escolas primárias baianas:

Para o ensino pratico das disciplinas que constituem o curso normal haverá devidamente providos do material necessario: Um gabinete de physica; Um laboratório de chimica; Um museu de historia natural; Um museu pedagógico; Um gabinete de hygiene geral e escolar anthropolo-pedagogica e psychologia experimental; Uma sala para desenhos; Um gabinete de dactylographia; Uma oficina para trabalhos de prendas; Uma oficina para trabalhos de economia domestica; Um pórtico gymnastico; Uma área pra gymnastica e jogos educativos ao ar livre; Um campo de experiencias para trabalhos de agricultura e jardinagem. (BAHIA, 1925, p. 201-202).

Ao observarmos esse indicativo, não identificamos um ambiente específico, como um laboratório, para o ensino de Matemática. Ao término do Curso Normal, os concluintes seriam agraciados com alguns itens, como prescrito:

Art. 163. O curso obrigatório de 4 annos da Escola Normal dará direito ao diploma de professor primario e ao uso de um anel symbolico, conferido pelo Director perante a Congregação.

Art. 164. A Congregação premiará, annualmente, cinco alumnos dentre os diplomados que mais se houverem distinguido, alcançando no mínimo dois terços de aprovações distinctas demonstrando decidida vocação para o magistério pelas melhores provas de capacidade pedagógica e de proficiência didactica, a par de procedimento exemplar.

Paragrapho único. Os alumnos premiados terão direito:

a) Ao diploma isento de todas as despesas;

b) A uma viagem de instrucção a outros Estados do Brasil;

c) A preferencia para ocupação de cadeiras do ensino publico (BAHIA, 1925, p. 204, grifo nosso).

A condecoração dos normalistas em prêmios como "uma viagem de instrucção a outros Estados do Brasil" talvez possa ser entendida por dois vieses: a) o intercâmbio entre os profissionais e intelectuais da educação dos estados brasileiros visavam uma troca de conhecimentos e experiências exitosas, adoção ou adaptação de modelos e sistemas de ensino, em prol de uma uniformização da educação escolar no país; b) sinal de que a Bahia não se encontrava em boas condições culturais escolares e emergia uma necessidade de se ir em busca de inovações pedagógicas. 
Demarcando a questão de gênero, o Artigo 136 sublinhou que "a não ser o ensino de prendas e Economia Domestica, exclusivamente ministrado por senhoras, todas as outras cadeiras poderão ser exercidas indistinctamente por professores ou professoras (BAHIA, 1925, p.201). Os Institutos Normais de Educação passaram a ter uma clientela predominantemente feminina. Uma demonstração é a constatação de que a Escola Normal da Bahia, em 1960, "foi frequentada no $1^{\circ}$ anno por 31 discipulos e 20 discipulas; no $2^{\circ}$ anno por 10 discipulos, e 16 discipulas. No fim do curso obtiverão cartas de habilitação 6 discipulos e 13 discipulas" (BAHIA, 1960, p.51). Um número bastante reduzido. Mas, como se configuravam os Programas de Ensino?

\section{Os Programas de Ensino de Matemática para a escola Primária E PARA OS CURSOS DE ForMAÇÃo de Professores na Bahia (1836-1960)}

Para analisarmos o ensino de Matemática tanto nas escolas primárias, quanto nos Cursos de Formação de Professores, é mister compreendermos o que D'Esquivel (et al., 2014, p. 21) enunciaram: "o estudo dos programas oficiais para o ensino de Matemática na escola primária representa uma das ações para entendimento do processo de constituição da Matemática como saber escolar no estado".

Ao que tudo indica, Magalhães (1848, p. 10, grifo nosso) foi o primeiro a pensar em uma reorganização da instrução primária, seguindo o exemplo da França e outros países da Europa, "digna de ser imitada pelos bons resultados", dividindo-a em duas: a) Instrucção elementar propriamente: "a leitura, calligrafia, rudimentos da Grammatica, noções elementares de Arithmetica, de Desenho Linear, do Cathecismo, e dos deveres Moraes do homem"; b) Instrucção elementar superior: "Grammatica completa da lingoa, Arithmetica, e noções de Algebra, a Geometria elementar, noções geraes da sciencias physicas, e naturaes, elementos de Geografia, da Historia pátria, e da Historia Biblica".

Em 1895, com o Ato Adicional, houve a instituição de um Conselho Superior de Ensino que, entre suas atribuições estava a de "approvar, elaborar, ou rever os programmas e adoptar ou rejeitar os meios de ensino, inclusive livros, compêndios, trabalhos de classe" (BAHIA, 1895, p. 43). Os Delegados Escolares deveriam "facilitar a vulgarisação dos methodos e meios proveitosos do ensino, ministrando aos professores occasiões de aprenderem ou se aperfeiçoarem na didactica moderna, já dirigindo exercícios nas escolas, já promovendo conferencias pedagógica populares" (BAHIA, 1895, p. 46).

A Constituição da Bahia, de 1895, no Artigo 107, § 2º, determinou: "as classes terão os mesmos programmas. Os cursos obedecerão ao mesmo plano de ensino, graduado de modo que os alumnos possam nos cursos médio e superior rever e completar os estudos feitos nos cursos anteriores". (BAHIA, 1895, p. 62). Assim, para a escola infantil, os saberes elementares matemáticos se reservaram à:

\begin{abstract}
Desenho: exercícios de combinação de linhas por meio de taboasinhas, pausinhos; exercícios de representação na ardósia apropriada dessas combinações e de desenhos fáceis, feitos pela mestra no quadro negro; exercícios de representação na ardósia, de objectos usuaes ou mais simples, e construções com a caixa Froebel;

Calculo: exercícios de numeração gradual, oral e escripta até 100 , e operações de somar, diminuir, multiplicar e dividir por meio de bolas, cubos, quadradinhos; exercícios para conhecer, nomear e dizer a utilidade das medidas métricas mais communs (BAHIA, 1895, p. 64, grifo nosso).
\end{abstract}

$\mathrm{Na}$ Escola Elementar, que se encontrava dividida em curso elementar, médio e superior, seguindo o Regulamento de 1895, os saberes elementares matemáticos eram basicamente Cálculo, Sistema métrico e Desenho (Quadro 1):

Quadro 1 - Saberes elementares matemáticos, Regulamento do Ensino Primário, Bahia, 1895

\begin{tabular}{|l|l|l|}
\hline Disciplina & Curso & Disposição \\
\hline $\begin{array}{l}\text { Calculo e systema } \\
\text { metrico } \\
\text { (BAHIA, 1895, p. 66). }\end{array}$ & Elementar & $\begin{array}{l}\text { Principios de numeração falada e escripta: somar, diminuir, multiplicar e dividir, até dois algarismos no } \\
\text { divisor; problema sobre as quatro operações. Noções praticas do systema métrico. }\end{array}$ \\
\cline { 2 - 3 } & Médio & $\begin{array}{l}\text { Revisão do curso antecedente. Divisão de numeros inteiros, operações sobre as fracções ordinárias e } \\
\text { decimaes. Sytema métrico. Problemas e applicações. }\end{array}$ \\
\cline { 2 - 3 } & Superior & $\begin{array}{l}\text { Numeros primos; divisibilidade dos numeros; regra de três simples; systema métrico. Problemas e } \\
\text { aplicações. }\end{array}$ \\
\hline $\begin{array}{l}\text { Desenho } \\
\text { (BAHIA, 1895, p. 68). }\end{array}$ & Elementar & $\begin{array}{l}\text { Desenho Linear. Traçado de Linhas rectas; sua divisão em partes eguaes; ângulos, triângulos e } \\
\text { quadriláteros; sua avaliação. }\end{array}$ \\
\cline { 2 - 3 } & Médio & $\begin{array}{l}\text { Desenho Linear. Representação das superfícies e volumes. Desenho á mão levantada. Princípios de } \\
\text { desenho geométrico. }\end{array}$ \\
\cline { 2 - 3 } & Superior & $\begin{array}{l}\text { Desenho Linear. Representação e avaliação dos volumes. Desenho á mão levantada, por modelos e } \\
\text { copias. Noções de desenho geométrico. }\end{array}$ \\
\hline
\end{tabular}

Fonte: Elaborado por Rosemeire Amaral, com base na Legislação Educacional da Bahia (1895, p. 66). 
Quadro 2 - Programas de Ensino das escolas primárias da Bahia (1913)

\begin{tabular}{|c|c|c|}
\hline 1a Classe & 2a Classe & $3^{\text {a }}$ Classe \\
\hline $\begin{array}{l}\text { a) Língua portuguesa; } \\
\text { b) Caligrafia; } \\
\text { c) Arithmetica e systema métrico; } \\
\text { d) Desenho de imitação geométrico; } \\
\text { e) Noções de geografia geral, geografia do } \\
\text { Brasil, especialmente da Bahia; } \\
\text { f) Historia do Brasil, especialmente da Bahia; } \\
\text { g) Elementos de sciencias physicas e naturaes, } \\
\text { aplicadas à agricultura e industrias; } \\
\text { H) ELEMENTos DE HYGIENe; } \\
\text { i) Civilidade; } \\
\text { j) Instrucção moral e cívica, sendo que as } \\
\text { letras h, i, j, por lições occasionaes; } \\
\text { k) Prendas domesticas para meninas; } \\
\text { 1) Callistenia sueca; } \\
\text { m) Cantigos e hynnos patrióticos. }\end{array}$ & $\begin{array}{l}\text { a) Língua portuguesa, falar, lêr, escrever, } \\
\text { formas grammaticaes; } \\
\text { b) Calligraphia; } \\
\text { c) Arithmetica, systema métrico; } \\
\text { d) Desenho de imitação e linear; } \\
\text { e) Noções de geografia geral, elementos de } \\
\text { geografia do Brazil, Geographia do Estado; } \\
\text { f) Historia do Brasil (elementos); } \\
\text { g) Prendas domesticas para meninas; } \\
\text { h) Lições occasionaes de civilidade, de } \\
\text { educação moral e cívica, de hygiene } \\
\text { elementar, de sciencias physicas e naturaes } \\
\text { aplicadas; } \\
\text { i) Callistenia sueca; } \\
\text { j) Cantigos e hynos patrióticos; }\end{array}$ & $\begin{array}{l}\text { a) Língua portuguesa, lêr e escrever; } \\
\text { b) Calligraphia; } \\
\text { c) Calculos das operações fundamentaes, } \\
\text { pezos e medidas usuaes; } \\
\text { d) Noções de Geographia geral e do Brazil, } \\
\text { Geographia do Estado; } \\
\text { e) Biografia de homens notáveis do Brazil; } \\
\text { f) Desenho linear; } \\
\text { g) Lições occasionaes de civilidade, de } \\
\text { educação moral e cívica, de hygiene } \\
\text { elementar, sobre agricultura e industria da } \\
\text { localidade; } \\
\text { h) Prendas domesticas para meninas; } \\
\text { i) Cantigos e hynnos escolares; } \\
\text { j) Callistenia sueca. }\end{array}$ \\
\hline
\end{tabular}

Fonte: Elaborado por Rosemeire Amaral, com base na Legislação Educacional da Bahia (1913, p. 136- 137).

Em 1913, uma nova configuração nos Programas de Ensino das Escolas Primárias da Bahia, respeitando a repartição em classes (Quadro 2).

Após esse panorama, é possível inferir que houve uma redução na ênfase dos saberes elementares matemáticos para a escola primária quando eram contempladas as noções elementares de Aritmética, de Desenho Linear, Aritmética, noções de Álgebra e Geometria elementar em 1848. Já nos anos entre 1895 e 1913, a Álgebra e a Geometria foram suprimidas. Sem embargo, em 1913, há uma divisão na matéria Desenho: Desenho de imitação geométrico (1 ${ }^{a}$ classe), Desenho de imitação e linear ( $2^{\underline{a}}$ classe $)$ e Desenho linear ( $3^{\underline{a}}$ classe).

Quanto aos programas de ensino utilizados na Escola Normal da Bahia, seguiam a prescrição da Lei no 1.846 , de 14 de agosto de 1925, quando o Artigo 121 sentenciou: "As escolas normaes, quer officies, quer equiparadas, gozarão de autonomia didactica, sendo desnecessária a identidade de programmas, exigida, porém, a equivalencia do ensino" (BAHIA, 1925, p. 198, grifo original).

Como observado nos Quadros 3 e 4, em uma continuidade nos programas de ensino das escolas normais da Bahia, os saberes elementares matemáticos (Aritmética, Álgebra, Desenho e Geometria) são inseridos no Curso de Formação de Professores da Bahia, em 1918 e 1925, nos primeiros três anos, visto que o Art. 130, da Lei no. 1.846, de 14 de agosto de 1925, dispôs que "o curso propedêutico ou de "habilitação pedagógica" visando sobretudo o preparo scientifico do alumno, em tres annos" (BAHIA, 1925, p. 199); o último ano deveria ser reservado para o curso profissional ou de "proficiência didactica" em que, propriamente, se ensinará a ensinar, intensificando-se o estudo da didactica, com exercício diário nas "escolas de applicação" anexas ao estabelecimento e o estudo de hygiene escolar, afim de dar ao futuro professor o conhecimento profundo da creança, fazendo-o comprehender praticamente que "o ensino deverá ser feito para o menino e não este para o ensino" (BAHIA, 1925, p. 199).

Quadro 3 - Distribuição das disciplinas para o Curso Normal da Bahia, 1918

\begin{tabular}{|l|l|}
\hline 1o Anno & 2o Anno \\
\hline a) Lingua portuguêsa; & a) Português; \\
b) Lingua francêsa; & b) Francês; \\
c) Arithmetica; & c) Arithmetica e Algebra; \\
d) Geografia, Cosmographia; & d) Chorographia do Brasil; \\
e) Pedagogia; & e) História Universal; \\
f) Prendas; & f) Pedagogia; \\
g) Desenho; & g) Prendas; \\
h) Gymnastica. & h) Desenho e Dactylographia. \\
\hline 3o Anno & 4o Anno \\
\hline a) Português; & a) Sciencias Naturaes; \\
b) Geometria e Escripturação & b) Noções de Hygiene, \\
c) Mercantil; & \multicolumn{1}{|c|}{ Anthropologia e Psychologia; } \\
d) Sciencias Physicas; Naturaes; & c) Economia politica e \\
e) Historia do Brasil; & Instrucção moral e civica; \\
f) Methodologia; & d) Pedagogia; \\
g) Pedagogia; & e) Methodologia; \\
h) Prendas (senhoras) e & f) Economia domestica; \\
i) trabalhos manuais (homens); & h) Musica; \\
i) Musica. & trabalhos manuais (homens). \\
\hline
\end{tabular}

Fonte: Elaborado por Rosemeire Amaral, com base na Legislação Educacional da Bahia (1918, p. $172-173)$. 
Quadro 4 - Distribuição das matérias do curso de Formação de Professores da Escola Normal, Bahia (1925)

\begin{tabular}{|l|l|}
\hline 1o Anno & 2o Anno \\
\hline a) Lingua portuguêsa; & a) Lingua portuguêsa; \\
b) Lingua francêsa; & b) Lingua francêsa; \\
c) Geografia geral, & c) Chorographia do Brasil; \\
Cosmographia; & d) Geometria; \\
d) Arithmetica e Algebra; & e) Physuca e Chimica; \\
e) Historia do Brasil; & f) Historia Universal; \\
f) Desenho e Calligraphia; & g) Desenho e Dactylographia; \\
g) Educação Physica; & h) Prendas; \\
h) Prendas; & i) Educação Physica; \\
i) Trabalhos manuais. & j) Trabalhos manuais. \\
3o Anno & 4o Anno \\
\hline a) Lingua portuguêsa e & a) Didactica pratica; \\
b) Literatura nacional; & b) Hygiene Escolar; \\
e Const., Educação Moral e & c) Canto coral; \\
c) Aivica; & e) Educação physica. \\
c) Hutomia e Physiologia & \\
d) Pedagogia e Psychologia & \\
e) Hygantil; & \\
f) Agricultura; & \\
g) Economia Domestica; & \\
h) Desenho; & \\
i) Educação Physica; & \\
k) Musica. &
\end{tabular}

Fonte: Elaborado por Rosemeire Amaral, com base na Legislação Educacional da Bahia (1925, p. 200-201).

Porém, no Artigo 125 do supracitado documento, há uma distribuição referente às vagas nos Institutos de Educação, uma vez que "a metade dos logares no primeiro anno será reservada aos alumnos das escolas elementares anexas à escola normal que tiverem obtido melhor classificação; preenchendo-se a outra metade mediante exame de suficiência" (BAHIA, 1925, p. 199). Essa estratégia possuía um objetivo maior, a formação de futuros professores pelas escolas normais oportunizava uma habilitação que viabilizasse uma nova roupagem à instrução pública primária, a partir do momento em que, conforme explicita do por Villela (2000, p. 109),

as escolas normais eram os locais "autorizados" para a difusão de um tipo de conhecimento normatizado que deveria caracterizar o "novo" professor primário, distinguindo-o dos seus antecessores, os "velhos" mestres-escolas, e alguns conteúdos foram se transformando num corpo de saberes característicos dessa formação.

A Lei no 1.846 , de 14 de agosto de 1925, instaurou na Bahia um Curso de Férias:
Art. 191. Na escola Normal se fará todos os annos um curso de férias, entre 1 e 20 de janeiro.

Art. 192. Terá por fim este curso indicar a orientação moderna do ensino primario e procurar estabelecer de modo preciso a finalidade e a correlação que devem existir entre as diversas disciplinas cogitando também dos assumptos que constituem interesse vital e progressista do ensino.

Art. 193. Constará este curso de conferencias, acompanhadas de demonstrações praticas sempre que o assumpto comportar.

Art. 194. Para fazerem estas conferencias serão enviados lentes e professores da Escola Normal e de outros estabelecimentos de ensino, como outras pessoas de notório saber (BAHIA, 1925, p. 208, grifo nosso).

A professora Julia Leitão, no primeiro Curso de Férias do Estado da Bahia, no ano de 1927, em uma Conferencia sob o título "O ensino de Mathemática na Escola Primaria", pronunciou: "[...] recordando-vos - e nunca é demais recordar - a grande importância do estudo da Arithmetica, que é, de todas as matérias ensinadas nas escolas primarias, a de maior utilidade na vida prática" (LEITÃO, 1927, p. 155). A referida docente sublinhou o status da Matemática na vida das pessoas analfabetas e dos sertanejos:

sem se saber ler nem escrever, mas, contudo, não se passa sem se saber contar. Assim os nossos mais rudes sertanejos, embora não saibam assignar o nome, nem de cruz, sabem quantos dias tem uma semana, quantas sementes devem lançar a cada cova, qual o preço dos vários gêneros alimentícios que compram ou vendem, etc. os nossos proprios selvagens contavam até cinco (LEITÃO, 1927, p. 155).

Leitão (1927, p. 157, grifo nosso) estendeu a importância de se aprender a Aritmética à outros campos do convívio humano, como as artes, a música (compassos), a Arquitetura, ao Desenho, a Poesia. Indo mais ao longe, no campo das ciências, as datas históricas, a Geografia (estimativas, cálculos de superfícies, extensões, altitude, profundidade, quantidade), a Astronomia (distância entre astros, órbitas, volumes), a Física (capacidade, temperatura, extensão dos corpos), a Química (valor quantitativo dos elementos). Embora esse elevado número de aplicações, a professora distinguiu que

é mister estudarmos a importância da Arithmetica, e é um factor indispensável da educação intellectual. [...] mas do que qualquer outra disciplina, ella força o alumno a reflectir, antes de responder; a procurar as relações entre as idéas, a comparar, antes de julgar e a só julgar por convecção própria; obriga-o a fixar a attenção sobre os dados que lhe são 
fornecidos; força-o-á contenção do espirito, quando se lhe pede a solução de determinado problema, pois elle sabe que um momento de distracção fal-o-á perder, não raro, todo o trabalho anterior.

Uma crítica bastante enfática quanto à condução do professor de Matemática na Escola Primária foi tecida por Leitão (1927, p. 158, grifo nosso), sob o uso da memória:

[...] como é preciso fazel-a trabalhar nas escolas; reproduzindo os conhecimentos que nella o raciocinio armazenou, conhecimentos adquiridos pela própria creança, com o auxilio do mestre e não embutidos na intelligencia infantil à força da repetição, não raro sob a pressão da palmatoria - preciosíssima auxiliar dos mestres que não sabem ensinar, que não procuram obter a colaboração dos discípulos, tornando o ensino activo, interessante, agradável aos alumnos e menos fatigante para o próprio mestre, que não precisará gritar para manter a disciplina na classe, nem cansar os braços em dar bolos e os dedos em dar cocorotes, quando uma ordem sua, sob a forma de um pedido, de um appello á razão dos discípulos - ouvi bem, de um appello á razão - pode obrar o milagre que os castigos physicos não conseguem.

Nesse contexto, passou a ser enfatizado os conhecimentos prévios e adquiridos pela criança no percurso escolar, a palmatória e outros castigos físicos foram condenados como antipedagógicos, e o ensino ativo - $\mathrm{o}$ aluno sendo o ponto de partida, com suas experiências, para a aprendizagem -, como o instrumento capaz de despertar o interesse do aluno e resultados exitosos para o trabalho do professor.

De acordo com Leitão (1927), a organização de um programa de estudos no ensino de Aritmética seria de "importância capital", cujo programa oficial determinava que os professores evitassem definições e utilizassem um caráter prático e intuitivo, seguindo a pedagogia de Maria Montessori (1870-1952), nas aulas elementares, com a ausência de contadores mecânicos, dever-se-ia explorar o cotidiano do aluno.

Após essas indicações, Leitão (1927) apresentou lições práticas de Matemática para o $1^{\circ}$ ano. A $1^{\text {a }}$ lição compreendeu: Operações fundamentais (Adição, subtração, multiplicação, divisão), teoria dos números (pares e ímpares, primos e múltiplos, fracionários). A $2^{\underline{a}}$ lição se compôs de um guia prático de como aplicar a lição 1á.: "o alumno, aprendendo raciocinar na Arithmetica, raciocinará também quando estudar as outras disciplinas do programma e ainda quando lhe antolharem as questões, por vezes, complicadíssimas da vida pratica" (LEITÃO, 1927, p. 198).

Assim, a Matemática escolar passou a compor um saber de utilidade não só educacional, como social. Um dos caminhos para a consolidação da Matemática nos anos de 1950-1960 foi o Movimento da Matemática Moderna (MMM) que, a princípio, não esteve voltada para a escola primária, mas "além de tópicos considerados modernos, as propostas dessa reforma envolveram a inserção de novas metodologias firmadas por um estatuto científico - psicológico, para aprender matemática" (ARRUDA, 2011, p. 28). De acordo Santana (2011, p. 22), inerente ao processo de modernização da Matemática escolar

\begin{abstract}
constavam a preparação dos professores, a partir das alterações promovidas no programa do secundário e suas articulações com o ensino primário e superior, e a confecção de livros nos quais se priorizava novo estilo de abordagem, de maneira que os esforços despendidos pelos professores motivassem as mudanças esperadas no ensino de Matemática.
\end{abstract}

Uma didática moderna era citada desde o ano de 1895, na Legislação da Bahia. Porém, foi com a implantação do MMM, integrando as escolas primárias aos cursos de formação de professores, que se consolidou na década de 1960.

\section{CONSIDERAÇõES FINAIS}

As reformas educacionais do Estado da Bahia dos anos de 1890, 1913, 1918 e 1925 e as determinações para estrutura e funcionamento do Ensino Primário e dos Institutos Normais de Educação, analisadas por intermédio da legislação educacional e das práticas pedagógicas entre 1836 e 1960 elaboram uma trajetória do ensino de Matemática no Brasil, em particular, na Bahia nos séculos XIX e XX.

A primeira legislação educacional na província da Bahia (1835), como Ato Adicional à Constituição de 1824, possibilitou a cada Província legislar sobre o Ensino Primário. A partir de 1830, os Relatórios de Administração Pública do Estado apresentaram as Fallas e Relatórios dos Presidentes provinciais do Império, os quais trouxeram as atribuições do governo em relação a diversos setores, em específico para a instrução pública. A descontinuidade das gestões devido ao tempo reduzido de permanência de cada presidente acarretou mudanças rápidas e bruscas no setor.

No entanto, houve um otimismo em relação à educação elementar, com a perspectiva de instalação de prédios escolares e do ensino mútuo, bem como o aumento do número de matrículas, particularmente, do sexo feminino que, mais tarde, ocuparia em massa os Institutos de Educação. Estes, por sua vez, passaram a exigir cada vez mais dos candidatos a futuros professores da Escola Primária, visto as Cadeiras vagas, e investindo em Cursos de Formação, iniciaram um intercâmbio 
externo (Brasil e França) e interno (entre Estados) em prol de conhecimento, adoção ou adaptação de modelos pedagógicos. Até então, os professores não se encontravam em uma situação confortável, quando desvalorizados, abandonavam suas cadeiras por vários motivos, dentre eles, melhores oportunidades no mercado de trabalho, deixando as escolas por conta de contratações indevidas, o que causou descrédito da instrução pública e a opção por instituições particulares, por parte dos pais ou responsáveis.

A Bahia contou, inicialmente, com três escolas normais: A Escola Normal da Bahia (1836), A Escola Normal de Caetité (1895) e A Escola Normal de Feira de Santana (1925). Todas passaram por extinções, reaberturas, mudanças curriculares, reformas, mudanças de prédio e outros.

Quanto aos Programas de Ensino de Matemática na Bahia, a Escola Primária transpôs as orientações pedagógicas das escolas anexas ao Instituto Normal. Em 1848, preocupou-se com as noções elementares de Aritmética, Aritmética, Desenho Linear, noções de Álgebra e Geometria elementar.

Em 1895, o Desenho e o Cálculo (oral e escrito) já prefiguravam o currículo do ensino infantil. $\mathrm{Na}$ escola elementar, Cálculo, Sistema métrico e Desenho para os três níveis elementar, médio e superior.

Em 1913, Aritmética, Sistema métrico e Desenho de imitação geométrico para as escolas de $1 \underline{a}$ classe (capital), Aritmética, Sistema métrico, Desenho de imitação e linear, Cálculos das operações fundamentais, Pesos e medidas usuais e Desenho linear para as escolas de $2^{\underline{a}} \mathrm{e}$ 3 a classes (interior).

Quanto aos programas de ensino utilizados na Escola Normal da Bahia, em 1918, Aritmética e Desenho (1ํㅡㄴ ano), Aritmética, Álgebra e Desenho ( $2^{\circ}$ ano), Geometria (3ํano). Para 1925, Aritmética, Álgebra e Desenho (1ํㅜㅇ ano), Geometria e Desenho (2 ano), Desenho ( $3^{\circ}$ ano). Assim, os saberes elementares matemáticos são inseridos no Curso de Formação de Professores da Bahia, em 1918 e 1925, nos primeiros três anos, visto que o $4^{\mathrm{O}}$ ano seria destinado à "proficiência didactica", enfatizando os conhecimentos prévios e adquiridos pela criança no percurso escolar, evitando recursos antipedagógicos como a palmatória e outros castigos físicos.

No ano de 1927, com novas abordagens e a inserção do Curso de Férias, o ensino de Matemática alcançou as Operações fundamentais (Adição, subtração, multiplicação, divisão), Teoria dos números (pares e impares, primos e múltiplos, fracionários), prevalecendo o uso do raciocínio e a relação da disciplina com outras matérias escolares e com o cotidiano do aluno.

O pensamento em uma didática moderna não é recente na Bahia, sendo citada na Legislação educacional desde
1895. Contudo, somente na década de 1960, o Movimento da Matemática Moderna (MMM) lançou propostas que envolveram novas metodologias e um estatuto científico - psicológico, para aprender matemática, inclusive para alcance do Ensino Primário e seu entrelaçamento com as escolas normais.

Assim, investigar a Formação de Professores e os Programas de Ensino de Matemática nos Institutos Normais de Educação e na Escola Primária da Bahia entre 1836 e 1960 se constitui uma valorosa contribuição para a História da Educação no Brasil, da Formação de Professores e do Ensino de Matemática nos séculos XIX e XX.

\section{Agradecimentos}

Agradecemos ao Grupo de Estudos em Educação Matemática (GEEM), a Universidade Estadual do Sudoeste da Bahia (UESB), a Universidade Federal de Santa Catarina (UFSC), a Universidade Federal de Sergipe (UFS), a Coordenação de Aperfeiçoamento de Pessoal de Nível Superior (CAPES) pelas valorosas contribuições e, em especial, ao Conselho Nacional de Desenvolvimento Científico e Tecnológico (CNPq), patrocinador do Projeto de Pesquisa intitulado "O ensino de Matemática no Curso Primário no Estado da Bahia: a caracterização de um percurso", processo no 0 407925/2016-3, modalidade APQ, vigência 01/06/2017 a 31/05/2020.

\section{REFERÊNCIAS}

ALMEIDA, T. X. G. Falla que recitou o presidente da província da Bahia, abertura da Assembléia Legislativa da mesma província. [Salvador]: Relatórios de Administração Pública do Estado, 1839. Disponível em: https://repositorio. ufsc.br/handle/123456789/104554. Acesso em: 1 dez. 2018. https://doi.org/10.5380/rv.v0i39.39238

AMARAL, R. S. A cultura escolar do ensino de matemática nos anos iniciais: um panorama nos grupos escolares em Anagé, Brumado e Guanambi - Bahia (1938-2000). 2015. Dissertação (Mestrado em Educação) - Programa de PósGraduação em Educação, Universidade Estadual do Sudoeste da Bahia, Vitória da Conquista, 2015. Disponível em: http:// www2.uesb.br/ppg/ppged/wp-content/uploads/2016/10/ DISSERTACAO-ROSEMEIRE-AMARAL .pdf. Acesso em: 7 jan. 2019. https://doi.org/10.18226/610001/mostraxvi.2016.45

ARAÚJO, J. C. S.; SOUZA, R. F.; PINTO, R. M. N. (org.). Escola primária na primeira república (1889-1930): subsídios para uma história comparada. Araraquara: Junqueira \& Marin, 2012.

ARRUDA, J. P. Histórias e práticas de um ensino na escola primária: marcas e movimentos da matemática moderna. 2011. Tese (Doutorado em Educação Científica e Tecnológica) - Programa de Pós-Graduação em Educação Científica e 
Tecnológica, Universidade Federal de Santa Catariana, Florianópolis, 2011. Disponível em: http://repositorio.ufsc. br/xmlui/handle/123456789/1807. Acesso em: 7 jan. 2019. https://doi.org/10.22533/at.ed.8591910066

ASSIS, D. L. M. A expansão do ensino secundário no Sul da Bahia na década de 50 e primeira metade da década de 60 do Século XX. In: CONGRESSO BRASILEIRO DE HISTÓRIA DA EDUCAÇÃO, 5., 2008, Aracaju. Anais [...]. Aracaju: [s.n.], 2008. Disponível em: http://www.sbhe.org.br/novo/ congressos/cbhe5/pdf/823.pdf. Acesso em: 4 dez. 2018. https://doi.org/10.4025/6cih.pphuem.685

AZEVEDO, P. J. M. Falla que recitou o excelentíssimo presidente da província da Bahia. [Salvador]: Relatórios de Administração Pública do Estado, 1841. Disponível em: https://repositorio.ufsc.br/handle/123456789/104557. Acesso em: 1 dez. 2018.

BAHIA. [Constituição (1895)]. Constituição do Estado da Bahia. [Salvador]: Palácio do Governo do Estado da Bahia, 1895. https://doi.org/10.20287/doc.d20.dt2

BAHIA. Lei n. 1.846, de 14 de agosto de 1925. Reforma a Instrucção Publica do Estado. [Salvador]: Imprensa Official do Estado, 1925.

BASTO, L. P. A. Senhores do Conselho Geral de Província Bahia: na typographia imperial e nacional. [Salvador]: Relatórios de Administração Pública do Estado, 1830. Disponível em: https://repositorio.ufsc.br/ handle/123456789/104553. Acesso em: 1 dez. 2018.

CRUZ, A. R. S. Mestras do sertão: a carreira docente de mulheres formadas pela Escola Normal de Feira de Santana entre 1930 e 1949. In: MACHADO, C. J. S.; SANTIAGO, I. M. F. L.; NUNES, M. L. S. (org.). Gêneros e práticas culturais: desafios históricos e saberes interdisciplinares. Campina Grande: EDUEPB, 2010. https://doi. org/10.7476/9788578791193.0015

\section{D'ANDREA, F. J. S. S. Falla dirigida a Assembléa} Legislative Provincial da Bahia. [Salvador]: Relatórios de Administração Pública do Estado, 1845. Disponível em: https://repositorio.ufsc.br/handle/123456789/104562. Acesso em: 1 dez. 2018.

D'AZEVEDO, A. I. Falla que recitou o presidente da provincia da Bahia. [Salvador]: Relatórios de Administração Pública do Estado, 1847. Disponível em: https://repositorio.ufsc.br/handle/123456789/104564. Acesso em: 1 dez. 2018.

D'ESQUIVEL, M. O. O ensino de desenho e geometria para a escola primária na Bahia (1835-1925). 2015. Dissertação (Mestrado em Educação Científica e Formação de Professores) - Programa de Pós-Graduação em Educação Científica e Formação de Professores, Universidade Estadual do Sudoeste da Bahia, Jequié, 2015. Disponível em: https://repositorio.ufsc.br/xmlui/handle/123456789/135021. Acesso em: 4 dez. 2018. https://doi.org/10.22169/revint. v13i28.1306
HILSDORF, M. L. S. Cultura escolar/ cultura oral em São Paulo (1820-1860). In: VIDAL, D. G.; HILSDORF, M. L. S. (org.). Brasil 500 anos: tópicos em história da educação. São Paulo: USP, 2001. https://doi.org/10.1590/s010288392001000200002

LEMOS, G. L. R. A Escola Normal na Bahia e a Educação Feminina. In: JORNADA HISTEDBR: história, sociedade e educação no Brasil: história da educação: intelectuais, memória e política, 10., 2011, Vitória da Conquista. Anais [...]. Vitória da Conquista: UESB, 2011. Disponível em: http://www.histedbr.fe.unicamp.br/acer_histedbr/jornada/ jornada10/_files/zRq4aLpK.pdf. Acesso em: 4 dez. 2018. https://doi.org/10.20396/rho.v16i69.8643876

LEITÃO, J. Conferencia sobre o ensino de Matemática. [Salvador: s. n.], 1927. Disponível em: https://repositorio. ufsc.br/xmlui/handle/123456789/135023. Acesso em: 5 dez. 2018.

MAGALHÃES, J. J. M. Falla que recitou o presidente da provincia da Bahia. [Slavador]: Relatórios de Administração Pública do Estado, 1848. Disponível em: https://repositorio.ufsc.br/handle/123456789/104566. Acesso em: 1 dez. 2018.

REIS, J. P. M. A escola Normal de Caetité na memória de professoras guanambienses. Revista Comciência, Guanambi, p. 65-73, 2007.

ROCHA, L. M. F. A Escola Normal na Província da Bahia. In: CONGRESSO BRASILEIRO DE HISTÓRIA DA EDUCAÇÃO: O Ensino e a Pesquisa em História da Educação, 5., 2008, Aracaju. Anais [...]. Aracaju: [s. n.], 2008. Disponível em: http://www.sbhe.org.br/novo/congressos/ cbhe5/pdf/10.pdf. Acesso em: 5 dez. 2018. https://doi. org/10.17648/galoa-cbee-6-30374

ROMANELLI, O. O. História da educação no Brasil (1930-1973). Petrópolis: Vozes, 1978.

SANTANA, I. P. A trajetória e a contribuição dos professores de matemática para a modernização da matemática nas escolas de Vitória da Conquista e Tanquinho (1960-1970). 2011. Dissertação (Mestrado em Ensino, Filosofia e História das Ciências) - Universidade Federal da Bahia, Universidade Estadual de Feira de Santana, Salvador, 2011. Disponível em: https://ppgefhc.ufba.br/sites/ ppgefhc.ufba.br/files/irani_parolin_santana__dissertacao_a_trajetoria_e_a_contribuicao_dos_professores_de.pdf. Acesso em: 5 dez. 2018. https://doi.org/10.23864/cppv1-n1-162

SOUSA, I. C. Padres educadores, abolicionismo e instrução pública na Bahia, 1878 a 1886. In: SIMPÓSIO NACIONAL DE HISTÓRIA - ANPUH, 26., 2011, São Paulo. Anais [...]. São Paulo: ANPUH, 2011.

VASCONCELLOS, J. J. P. Falla que recitou o presidente da provincia da Bahia. [Salvador]: Relatórios de Administração Pública do Estado, 1843. Disponível em: https://repositorio. ufsc.br/handle/123456789/104560. Acesso em: 1 dez. 2018. 
VASCONCELLOS, J. J. P. Falla que recitou o presidente da provincia da Bahia. [Salvador]: Relatórios de Administração Pública do Estado, 1844. Disponível em: https://repositorio.ufsc.br/handle/123456789/104561. Acesso em: $1 \mathrm{dez} .2018$.

VILLELA, H. O. S. O mestre-escola e a professora. In: LOPES, E. M. T.; FARIA FILHO, L. M.; VEIGA, C. G. 500 anos de educação no Brasil. 2. ed. Belo Horizonte: Autêntica, 2000.

Recebido em: 3/5/2019.

Aprovado em: 15/5/2019.

Publicado em: 8/11/2019.

Endereço para correspondência:

Rosemeire dos Santos Amaral

Estrada do Bem-Querer, s/n. - Bairro Universitário

45031-900, Vitória da Conquista, BA, Brasil

\section{Autores:}

ROSEMEIRE Dos SANTOS AMARAL

Doutoranda em Educação, Bolsista Capes, na Universidade Federal de Sergipe (UFS), Aracaju, BA, Brasil. Mestra em Educação pela Universidade Estadual do Sudoeste da Bahia (UESB), Vitória da Conquista, BA, Brasil. Graduada em Licenciatura Plena em História pela Universidade Estadual do Sudoeste da Bahia (UESB), Vitória da Conquista, BA, Brasil. Professora do Ensino Básico do Estado da Bahia.

Orcid: http://orcid.org/0000-0001-7716-6453

E-mail: roseamaral25@gmail.com

Irani Parolin Santana

Doutora em Educação Matemática pela Universidade Anhanguera de São Paulo (UNIAN), com Estágio na Université de Lyon II - França. Mestre em Ensino, Filosofia e História das Ciências pela Universidade Federal da Bahia (UFBA), Salvador, BA, Brasil e Universidade Estadual de Feira de Santana (UEFS),

Feira de Santana, BA, Brasil. Especialista em Matemática para Professor do Ensino em Educação Infantil e Fundamental pela Universidade Estadual de Campinas (Unicamp), Campinas, SP, Brasil e em Informática em Educação pela Universidade Federal de Lavras (UFLA), Lavras, MG, Brasil. Licenciada em Matemática pela Pontifícia Universidade Católica de Campinas (PUC-Campinas), Campinas, SP, Brasil. Professora e coordenadora da Área de Educação Matemática na Universidade Estadual do Sudoeste da Bahia (UESB), Vitória da Conquista, BA, Brasil. Integrante do Grupo de Estudos em Educação Matemática (GEEM), do Programa de Extensão Ações Colaborativas e Cooperativas em Educação (ACCE) e da Sociedade Brasileira de Educação Matemática na Bahia (SBEM/Ba), Salvador, BA, Brasil. Orcid: http://orcid.org/0000-0002-1857-3638

E-mail: iranips@gmail.com

Claudinei de Camargo Sant'Ana

Doutor em Educação pela Universidade Estadual de Campinas (Unicamp),

Campinas, SP, Brasil, com estágio de pós-doutoramento na Universidade Estadual Paulista Júlio de Mesquita Filho, UNESP, Rio Claro, SP, Brasil e estágio de pós-doutoramento na Université de Limoges Faculté des Sciences et Techniques, Limoges, França. Mestre em Engenharia Mecânica pela Universidade Estadual de Campinas (Unicamp), Campinas, SP, Brasil. Especialista em Informática em Educação pela Universidade Federal de Lavras (UFLA), Lavras, MG, Brasil. Licenciado em Matemática pela Pontifícia Universidade Católica de Campinas (PUC-Campinas), Campinas, SP, Brasil, em Pedagogia pela Faculdade de Ciências e Letras Plínio Augusto do Amaral (FCLPAA), Amparo, SP, Brasil e especialista em Informática em Educação pela Universidade Federal de Lavras (UFLA), Lavras, MG, Brasil.

Orcid: http://orcid.org/0000-0003-1429-4559

E-mail: claudinei@ccsantana.com 